\title{
Working with Dental Organizations: JDSM Interview with Dr. Prabu Raman
}

Disclaimer: The use, mention or depiction of any product, device, service or appliance shall not be interpreted as an endorsement, recommendation or preference by the AADSM. Any opinion expressed is solely the opinion of the individual, and not that of the AADSM.

Recently, the Journal of Dental Sleep Medicine had the privilege of interviewing Prabu Raman, DDS, D.ABDSM, a Kansas City-based dentist and member of the AADSM. We discussed his recent experience working with the American Dental Association (ADA) House of Delegates, as well as his experiences with other dental organizations.

\section{WHAT HAS YOUR EXPERIENCE BEEN WORKING WITH THE ADA?}

"I have been a member of the ADA from the moment I graduated from University of Missouri - Kansas City in 1983. I volunteered more time after our children were grown, as I felt an obligation to serve the profession that has given me so many opportunities. Nearly $70 \%$ of all licensed dentists are ADA members. This gives ADA the authority to speak for dentists and the ability to advocate for dentistry at the national, as well as state levels. Of course, I don't agree with every position that ADA takes on issues. But for those who are willing to spend their time and energy, there are lots of opportunities to serve and be involved when decisions are made that may have long lasting impact on the profession. I have had the opportunity to meet and work with dedicated volunteer dentists from around the country. I have served on the Council on Dental Education and Licensure (CDEL) for 4 years, as well as served on various task forces and committees including the Steering Committee that guided the creation of Dental Licensure Objective Structured Clinical Examination (DLOSCE). I currently serve as a Commissioner on National Commission on Recognition of Dental Specialties and Certifying Boards."

YOU RECENTLY SUPPORTED THE UPDATING OF THE ADA'S POLICY ON DENTISTS' INVOLVEMENT IN THE TREATMENT OF SLEEP-RELATED BREATHING DISORDERS (SRBDS) AT THE ADA HOUSE OF DELEGATES MEETING - CAN YOU TELL US WHAT THIS PROCESS WAS LIKE?
"The ADA House of Delegates (HOD), comprised of 483 delegates, is the legislative and governing body of the ADA and is the supreme authority guiding the American Dental Association. It meets once a year. Delegates are volunteer dentists elected by their state dental associations. I have served as an active delegate representing Missouri for 12 years as part of the 6th Trustee district. ADA policies are implemented by the ADA staff, guided by the officers and Board of Trustees. The officers and board represent each of the 17 Trustee districts, who are elected by the Delegates. 10 ADA Councils, which are considered to be committees of the HOD, function throughout the year and have an advisory role. The Council on Dental Practice (CDP) was referred a resolution by the 2015 HOD directing it to create a policy on dentistry's role in SRBD. 2017 HOD adopted the policy proposed by CDP after two years of work drawing on the expertise from communities of interest including AADSM. The CDP proposed amendments to that policy in 2021 aimed at increasing access to SRBD treatment and were presented as Resolution (RC) 42 to the 2021 HOD. Resolutions to the HOD are assigned to the appropriate reference committee for a hearing where everyone is allowed to give testimony to support, oppose or propose changes. Reference Committee B (Dental Benefits, Practice and Related Matters) heard 'Pro' testimony supporting the resolution from AADSM President Dr. David Schwartz, AADSM President Elect Dr. Mitchell Levine, myself and others. There were also a few "cons" testimonies given. The reference committee considered the comments and presented Resolution $42 \mathrm{RC}$ as part of a 'consent agenda'. I was in continual communication with Drs. Schwartz, Levine and Ms. Becky Roberts, AADSM Executive Director.

All the resolutions that are grouped as consent agenda are typically passed as a block. However, a single delegate may request a particular resolution be removed from consent for further debate or changes. A delegate from South Carolina removed $42 \mathrm{RC}$ from the consent agenda and wanted to add language specifying "sleep" physicians. 
When a resolution is debated on the floor of the HOD, amendments can be made to do wordsmithing and sometimes end up with a sub-optimal final resolution. Drs. Levine and Schwartz provided me information, in real time, about the relatively small number of sleep medicine specialists as well as their concentration in cities and academic institutions, which makes them inaccessible for rural patients. I was then able to address the HOD and successfully advocate for the defeat of that change, since patients in rural Missouri, Kentucky, Tennessee and West Virginia that comprise 6th district would be prevented from receiving care for their SRBD in a timely manner. The resolution passed unanimously after another amendment that further improved language on follow up testing. The final resolution is in support of the dentist ordering sleep apnea testing in accordance with applicable laws. Any efforts in the states to effect these changes through legislation or rule changes would be tremendously helped since they are supported by ADA policy."

\section{WHAT HAS YOUR EXPERIENCE BEEN WORKING WITH STATE-LEVEL DENTAL ASSOCIATIONS?}

"Ample opportunities are available for dentists who are engaged and are willing to serve. In fact, most societies, such as the Greater Kansas City Dental Society are eager to give leadership positions for active members. I served on the board of directors and as President of GKCDS. Similarly, at the state level there are opportunities to serve and hold leadership positions. I have served as a member of the Missouri Dental Association HOD, served on the MDA Board of Trustees and as President of the Missouri Dental Association in 2017. I currently serve as a Director of the Missouri Dental Insurance Services - a wholly owned subsidiary of the MDA. I have enjoyed working with dedicated volunteer dentists from around the state by focusing on what we share in common for the future of dentistry instead of on any differences we may have in practice philosophy or practice models."

\section{WHAT ARE SOME BENEFITS AND OPPORTUNITIES FOR OUR MEMBERS TO GET MORE INVOLVED WITH THESE KINDS OF ORGANIZATIONS?}

"The primary benefit of being an active member of the ADA at local, state or national level is one of service to the profession. This profession has given all dentists countless opportunities, and we must preserve it for the generations of dentists to follow us. But there are other benefits. One of the often-repeated cliches is "if you are not at the table, you are on the menu." A corollary could be, "If you are not at the table, you don't have any influence." If we want things to change for the better and improve, we need to be willing to volunteer our time, energy and funds to contribute to political action committees. I believe that being a leader in your professional organization gives credibility and respect in the eyes of potential and existing patients. They appreciate that their dentist is an involved member of his or her profession and that it is more than just a way to make a good living. I also believe that being a leader in one's state dental association places you in a positive light in the eyes of the dental board members who after all are dentists from this state as well. That is always a good thing."

\section{CITATION}

Working with dental organizations: JDSM interview with Dr. Prabu Raman. J Dent Sleep Med. 2022;9(1). 


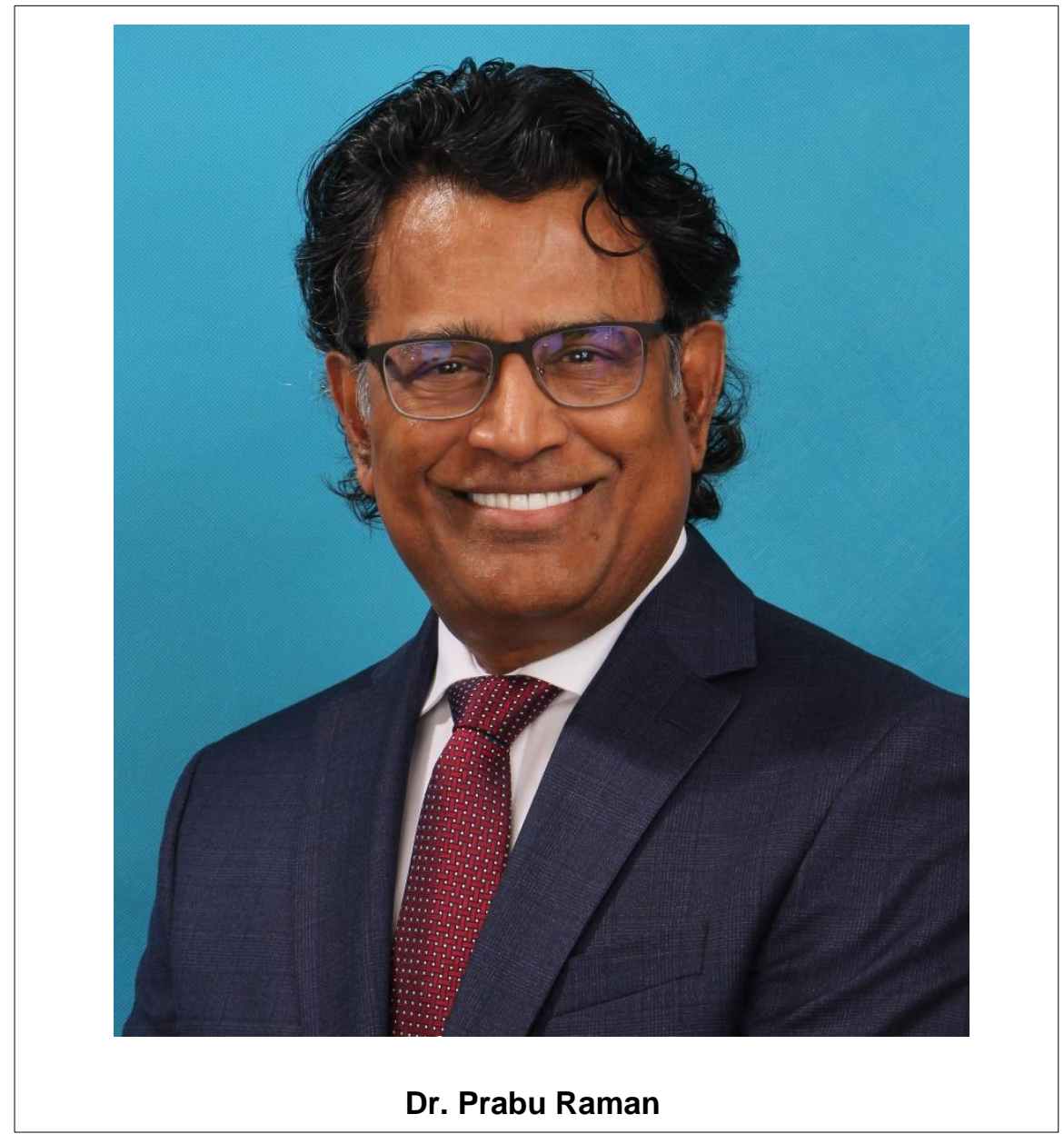

